\title{
Green Synthesis: A Novel Method for Bromination of 7-Amino- Phthalide
}

\author{
Gondi Sudershan Reddy ${ }^{1^{*}}$
}

\begin{abstract}
Affiliations:
${ }^{1}$ Departments of Chemistry, National Taiwan Normal University, Taipei, Taiwan 116 (ROC).

a Correspondence to: gondisr@gmail.com.
\end{abstract}

\begin{abstract}
A novel method for preparing a bromo substituted 7-Amino-phthalides and 7Amino-3-hydroxy-phthalides via the bromonium ion intermediate under acidic conditions at higher temperature were developed. The results will illustrate the potential utility of this method as an environment-friendly process for synthesis of bromo substituted aryl amines, along with conservation of half mole equivalent of halides.
\end{abstract}

Key words: 7-Amino-phthalide, bromonium ion, desulfonation, green chemistry, Introduction: Much attention has been given in recent years to the preparation of halide substituted phthalide ${ }^{1,2}$ because such molecules occur widely in natural products ${ }^{3-5}$ which display a wide variety of significant biological activity. They have also been employed as key intermediate for the synthesis of natural products ${ }^{6}$ and useful pharmaceuticals value products namely citralophram ${ }^{7}$ 2-phenylbenzimidazole-4-carboxamide ${ }^{8}$ and Remoxipride analogues $^{9}$ Phthalides are transformed into number of other functional groups, namely Isoquinazoline, ${ }^{10}$ furan derivatives, ${ }^{11}$ phthalzine,${ }^{12}$ phtlimide,${ }^{13}$ and phthalide-3-OH derivatives, ${ }^{14}$ indeed the phthalides-3-OH groups are converted into biological active molecules for studies in 5-HTR receptors, ${ }^{15}$ antileishmanial ${ }^{16}$, in Alzheimer therapy, ${ }^{17}$ topoisomerase, ${ }^{18,19}$ antidiabetic agents, ${ }^{20}$ PARP inihibitors ${ }^{21}$, Leukotriene receptors agonst ${ }^{22}$ and antiproliferative activity. ${ }^{23} \mathrm{~A}$ 
variety of efficient synthetic methods have been reported on the synthesis of phthalides. ${ }^{24} 25$ However, while these are of great value, there is still a need for new method which would allow us to obtain phthalides, particularly bromo substituted 7-Amino phthalides in an environment-friendly manner, where there is no single procedure is reported. The development of new methods that to with green chemistry protocols therefore continues to be an important area of research. The purpose of this paper is to describe the novel method for synthesis of bromo substituted 7-Amino phthalides and 7-Amino hydroxy-phthalide in an environment eco-friendly manner with conserve the half mole equivalent of halides.

Present Work: Methyl 2-N-methyl- 2-N-tosyl-6-nitroanthranilate on treatment with concentrated sulfuric acid $(3 \mathrm{~mL})$ heated at $100^{\circ} \mathrm{C}$ for 30 minutes gives free amine by desulfonation are well documented ${ }^{26}$. In another reported methods ${ }^{27}$, 4-nitrophthalide is formed from methyl-2-bromomethyl-4-nitro-benzoate by using concentrated sulfuric acid (at $\left.100^{\circ} \mathrm{C}\right)$ under distillation conditions.

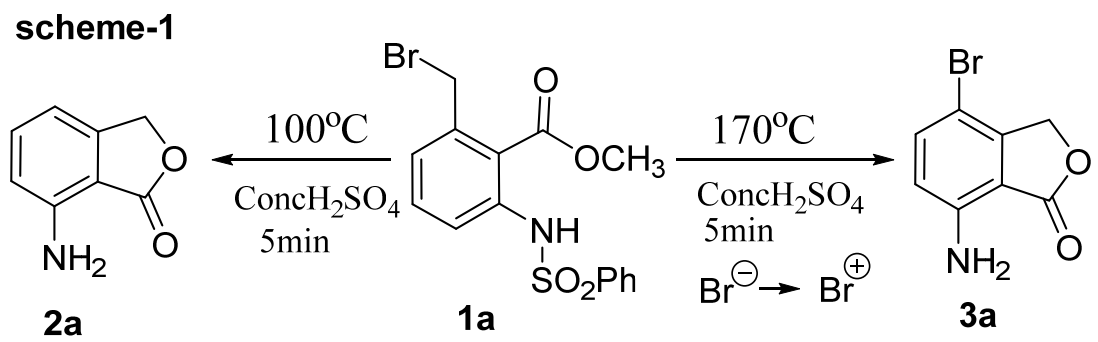

After observing these two reactions, we treated compounds 1a (scheme-1) having benzylic bromo and sulfonamide group treated under similar condition, as expected we isolated the 2a. It is understood that phthalide ring is formed, due of hydrolysis of methyl ester, the in situ generated carboxylic ion on nucleophilic attack on bromo bearing benzylic carbon, leaving the bromide ion, and followed by desulfonation to obtained 7-Amino-3H-isobenzofuran-1-one (2a). To utilize the oxidation potentials of bromine and iodine in reducing the sulfuric acid, we done a series of reaction with variation in temperature. To our surprise, when the temperature 
at $170^{\circ} \mathrm{C}$, we isolated the 7 -Amino-4-Bromo-3H-isobenzofuran-1-one (3a). it proved $170^{\circ} \mathrm{C}$, its critical temperature where the liberated bromide ion act as reducing agent ${ }^{28}$ to reduce the sulfuric acid and itself oxidized to bromine/bromonium ion, which undergoes electrophilic bromination on 7-Aminophthalide (2a) to give product $\mathbf{3 a}$. In this protocol, resulting in a no bromine content in the wastewater and also avoiding the sulfonated products as impurities ${ }^{29}$.
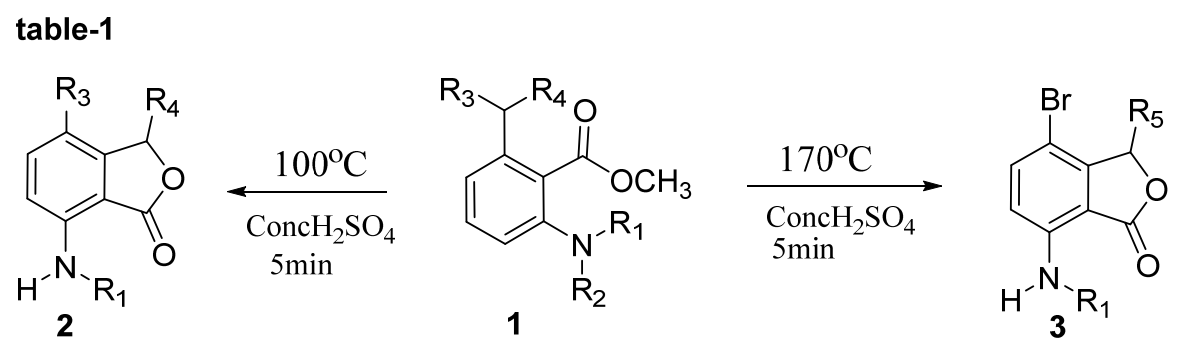

\begin{tabular}{|c|c|c|c|c|c|c|c|c|}
\hline Entry & Substrate & $\mathbf{R}_{\mathbf{1}}$ & $\mathbf{R}_{\mathbf{2}}$ & $\mathbf{R}_{\mathbf{3}}$ & $\mathbf{R}_{\mathbf{4}}$ & $\mathbf{R}_{\mathbf{5}}$ & $100^{\circ} \mathrm{C}$ Yield (\%) & $170^{\circ} \mathrm{C}$ Yield (\%) \\
\hline 1 & $1 a$ & $\mathrm{H}$ & $\mathrm{SO}_{2} \mathrm{Ph}$ & $\mathrm{Br}$ & $\mathrm{H}$ & $\mathrm{H}$ & 2a, 90 & $3 a, 93$ \\
\hline 2 & $1 b$ & $\mathrm{H}$ & $\mathrm{SO}_{2} \mathrm{Ph}$ & I & $\mathrm{H}$ & $\mathrm{H}$ & $2 a, 87$ & $3 b, 05$ \\
\hline 3 & $1 \mathrm{c}$ & $\mathrm{H}$ & $\mathrm{SO}_{2} \mathrm{Ph}-4 \mathrm{CH}_{2} \mathrm{Br}$ & $\mathrm{Br}$ & $\mathrm{H}$ & $\mathrm{H}$ & $2 a, 89$ & $3 a, 91$ \\
\hline 4 & $1 d$ & $\mathrm{H}$ & $\mathrm{SO}_{2} \mathrm{Ph}-4 \mathrm{NO}_{2}$ & $\mathrm{Br}$ & $\mathrm{H}$ & $\mathrm{H}$ & $2 a, 90$ & $3 a, 90$ \\
\hline 5 & $1 e$ & $\mathrm{CH}_{3}$ & $\mathrm{SO}_{2} \mathrm{Ph}$ & $\mathrm{Br}$ & $\mathrm{H}$ & $\mathrm{H}$ & $2 e, 91$ & $3 e, 91$ \\
\hline 6 & $1 f$ & $\mathrm{CH}_{3}$ & $\mathrm{SO}_{2} \mathrm{Ph}$ & $\mathrm{Cl}$ & $\mathrm{H}$ & $\mathrm{H}$ & $2 e, 89$ & NR \\
\hline 7 & $1 \mathrm{~g}$ & $\mathrm{CH}_{3}$ & $\mathrm{SO}_{2} \mathrm{Ph}-4 \mathrm{CH}_{2} \mathrm{Br}$ & $\mathrm{Br}$ & $\mathrm{H}$ & $\mathrm{H}$ & $2 e, 90$ & $3 e, 90$ \\
\hline 8 & $1 \mathrm{~h}$ & $\mathrm{CH}_{3}$ & $\mathrm{SO}_{2} \mathrm{Ph}-4 \mathrm{NO}_{2}$ & $\mathrm{Br}$ & $\mathrm{H}$ & $\mathrm{H}$ & $2 e, 91$ & $3 e, 90$ \\
\hline 9 & $1 \mathrm{i}$ & $\mathrm{CH}_{3}$ & $\mathrm{SO}_{2} \mathrm{Ph}$ & $\mathrm{OCH}_{3}$ & $\mathrm{H}$ & $\mathrm{H}$ & $2 e, 81$ & NR \\
\hline 10 & $1 \mathrm{j}$ & $\mathrm{H}$ & $\mathrm{SO}_{2} \mathrm{Ph}$ & $\mathrm{Br}$ & $\mathrm{Br}$ & $\mathrm{OH}$ & $2 \mathrm{j}, 91$ & $3 \mathrm{j}, 85$ \\
\hline
\end{tabular}

Encouraged by this result, we investigated these procedures with a variety of benzyl halides (table 1 ) to explore the generality of this system (see table 1). At $100^{\circ} \mathrm{C}$ all substrates $(1 \mathrm{a}-1 \mathrm{j})$ given the phthalide (2a and $\mathbf{2 e}$ ) in excellent yield, whereas at higher temperature, the benzyl bromo gives excellent yield of bromo substituted 7-Aminophthalides (3a and $\mathbf{3 e}$ ). The structures (3a and $\mathbf{3 e}$ ) was proved by single crystals data. In case of Benzyliodo (1b), gives iodo substituted 7-Aminophthalide (3b) but yield is poor (5\%). It can be explained as, even though lodide ion is oxidized to iodine/iodonium ion in sulfuric acicd, due to higher temperature it sublimes before it reacts with 7-amino phthalide (2a). In case of chloro substrate (1f), the liberated chloride ion form $\mathrm{HCl}$, due to inability of sulfuric acid to oxidize 
the chloride ion to chloronium ion (or chlorine gas). The CBZ protected aniline with methoxy group $^{30}$ (1i) does not given any corresponding anisole derivatives, even prolong the reaction time at higher temperature. Substituted on benzene sulfonate group (1c,1d, and $\mathbf{1 f}, \mathbf{1} \mathbf{g})$ are also giving the same results $(\mathbf{2 a}$ and $\mathbf{2 e})$. When dibromo substrate ${ }^{31}(\mathbf{1 j})$ under these conditions gives $\mathbf{2} \mathbf{j}$ (not isolated) and $\mathbf{3} \mathbf{j}$, respectively. During the formation of $\mathbf{3} \mathbf{j}$, it is understood that 3-bromo phthalide is first formed, followed by hydrolysis to give the 3hydroxy-7-Aminophthalide. This study clearly shows that other halogens, chlorine (sulfuric acid unable to oxidize) and iodine (sublime properties) are not effective as bromine. Finally, the temperature factor is significant since at $100^{\circ} \mathrm{C}$, irrespective of halogenated substrates, the intermediate phthalides $\mathbf{2 a}, \mathbf{2 e}$ and $\mathbf{2} \mathbf{j}$ (not isolated) is formed, and whereas at $170^{\circ} \mathrm{C}$, formation of halide substituted 7-amino phthalide is depends on halogenated substrate.

table-2

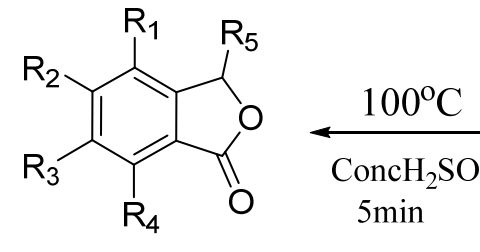

2<smiles>[R]Nc1c([R])c([R])c(C(=O)OC)c(C([R6])Br)c1[R4]</smiles>

1
3

\begin{tabular}{|c|c|c|c|c|c|c|c|c|}
\hline Entry & Substrate & $\mathbf{R}_{1}$ & $\mathbf{R}_{\mathbf{2}}$ & $\mathbf{R}_{\mathbf{3}}$ & $\mathbf{R}_{\mathbf{4}}$ & $\mathbf{R}_{5}$ & $100^{\circ} \mathrm{C}$ Yield (\%) & $170^{\circ} \mathrm{C}$ Yield (\%) \\
\hline 1 & $1 \mathrm{k}$ & $\mathrm{H}$ & $\mathrm{H}$ & $\mathrm{H}$ & $\mathrm{H}$ & $\mathrm{Br}(\mathrm{OH})$ & $2 \mathrm{k}, 91$ & $\operatorname{mix}$ \\
\hline 2 & 11 & $\mathrm{H}$ & $\mathrm{H}$ & $\mathrm{H}$ & $\mathrm{H}$ & $\mathrm{H}$ & 21,93 & $\operatorname{mix}$ \\
\hline 3 & $1 \mathrm{~m}$ & $\mathrm{H}$ & $\mathrm{H}$ & $\mathrm{H}$ & $\mathrm{NO}_{2}$ & $\mathrm{H}$ & $2 m, 85$ & NR \\
\hline 4 & $1 \mathrm{n}$ & $\mathrm{H}$ & $\mathrm{H}$ & $\mathrm{NO}_{2}$ & $\mathrm{H}$ & $\mathrm{H}$ & $2 n, 89$ & NR \\
\hline 5 & 10 & $\mathrm{NO}_{2}$ & $\mathrm{H}$ & $\mathrm{H}$ & $\mathrm{H}$ & $\mathrm{H}$ & 2o, 91 & NR \\
\hline 6 & $1 p$ & $\mathrm{H}$ & $\mathrm{NO}_{2}$ & $\mathrm{H}$ & $\mathrm{H}$ & $\mathrm{H}$ & $2 p, 88$ & NR \\
\hline
\end{tabular}

When unsubstituted benzyl dibromo (ik) and benzyl bromo (1I) (table-2), treated under similar condition, as expected the $3-\mathrm{OH}$ phthalide $(\mathbf{2 k})$ and phthalide $(\mathbf{2 I})$ are formed $100^{\circ} \mathrm{C}$, but when on heating at $170^{\circ} \mathrm{C}$, inseparable mixture of product is formed. In case of nitro substituted benzyl bromides (1m,1n and 10), only nitro-phthalides $(2 \mathrm{~m}, 2 \mathrm{n}$ and 20 ) are formed at $100^{\circ} \mathrm{C}$, whereas no brominated nitro-phthalides were isolated at $170^{\circ} \mathrm{C}$. it clearly 
shows neither nucleophilic bromination at $100^{\circ} \mathrm{C}$ and nor electrophilic bromination at $170^{\circ} \mathrm{C}$ occurs.

table-3
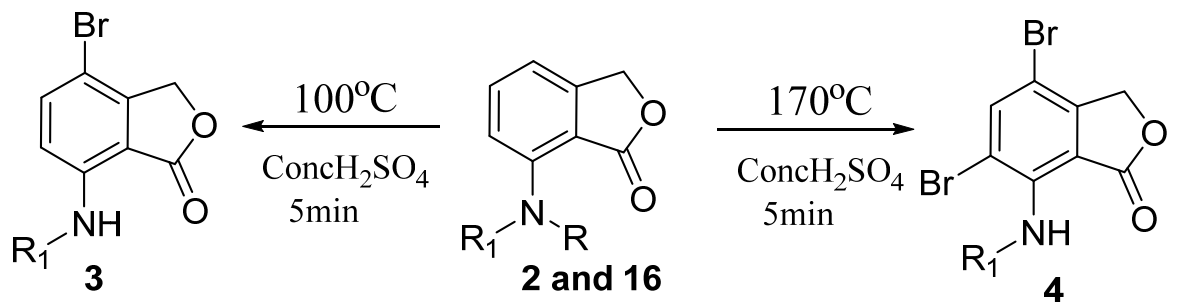

\begin{tabular}{|cccccc|}
\hline Entry & Substrate & $\mathbf{R}$ & $\mathbf{R}_{\mathbf{1}}$ & Yield (\%) & Yield (\%) \\
\hline 1 & $2 \mathrm{a}$ & $\mathrm{H}$ & $\mathrm{H}$ & $3 \mathrm{a}, 91$ & $4 \mathrm{a}, 92$ \\
2 & $2 \mathrm{e}$ & $\mathrm{H}$ & $\mathrm{CH}_{3}$ & $3 \mathrm{e}, 90$ & $4 \mathrm{e}, 91$ \\
3 & 16 & $\mathrm{SO}_{2} \mathrm{Ph}$ & $\mathrm{CH}_{3}$ & $3 \mathrm{e}, 89$ & $4 \mathrm{e}, 90$ \\
\hline
\end{tabular}

Bromine as external source: Independently, the 7-Amino phthalide ( $2 \mathbf{a}$ and $2 \mathbf{2}$ ), and its sulfonated substrate (16) on treatment (table-3) with 1.0 eq of bromine in conc sulfuric acid at $100^{\circ} \mathrm{C}$ obtains the mono brominated 7-Aminophthalides (3a and $3 \mathbf{e}$ ), this is due to availability of bromonium ion by cleavage of bromine molecules, whereas at $170^{\circ} \mathrm{C}$ as expected we isolated the dibromo derivatives $4 \mathbf{a}$ and $4 \mathbf{e}$ respectively. These products (4a and $4 \mathbf{e}$ ) formation further suggest bromide ion is oxidized to bromine/bromonium ion in conc sulfuric acid at $170^{\circ} \mathrm{C}$ and facilitate electrophilic bromination. Further the $\mathbf{4 a}$ is proved by single crystals data. When 4-aminopthalide (17) (shown in supplementary part) is under these conditions gives inseparable mixture, due to mismatching effect of amine/carbonyl groups on the incoming group.

The reaction is exceptionally clean and easy workup is required to obtained spectrally pure substances. No side products were isolated from any reaction. However, despite its utility and simplicity, limitations are sometimes encountered, particularly with acid sensitive benzyl bromide substrates, which are cleaved in acidic medium. 
In conclusion, we have found a novel method for preparing a bromo substituted 7-amino phthalide and its 3-hydroxy derivatives via the bromonium ion intermediate under acidic conditions. The results illustrate the potential utility of this method as an environment-friendly process with conserve the half mole equivalent of halide. The obtained products were useful in fluorescence probe study to modify the cysteine and its application to protein modifications $^{32}$.

\section{- Corresponding Author Information}

Corresponding Author: Gondi Sudershan Reddy, email: gondisr@gmail.com

\section{- Acknowledgement}

G.S.R thankful to National Science Council of Taiwan, (ROC) for financial support in the form of Post-Doctoral Fellowship during February 2000-July 2003. G.S.R is thankful to Chang I jy and Kwunmin Chen at National Taiwan Normal University, Taipei, Taiwan, for conducting the experiments and collection and processing of the spectral data and X-ray data are gratefully acknowledged.

- Competing interests: There is no Competing Interests pending

Data and materials availability: Crystallographic model data is available through the CCDC under identifier 2004667 (2-Bromomethyl-6-[methyl-(4-nitro-benzenesulfonyl)-amino]-benzoic acid methyl ester, 1h), 1990752 (2-Benzenesulfonylamino-6-dibromomethyl-benzoic acid methyl ester, 1j), 2004106 (isobenzofuran-1(3H)-one, 2I), 1990762 (7-Amino-4-bromo-3Hisobenzofuran-1-one, 3a), 1990754 (4-Bromo-7-methylamino-3H-isobenzofuran-1-one, 3e), 1990759 (7-Amino-4,6-dibromo-3H-isobenzofuran-1-one, 4a), 2004668 (Benzenesulfonylmethylamino)-6-methyl-benzoic acid methyl ester, 10), 2004669 (2-Methyl6-[methyl-(4-nitro-benzenesulfonyl)-amino]-benzoic acid methyl ester, 12) and 1990780, VABSAW, N-Methyl-N-(3-oxo-1,3-dihydro-isobenzofuran-4-yl)-benzenesulfonamide (16). 


\section{Reference:}

1 Moriarty, R. M., Vaid, R. K., Hopkins, T. E., Vaid, B. K. \& Prakash, O. Conversion of lactones to the higher homologous $\alpha, \beta$-unsaturated lactones $\mathrm{v} / \mathrm{a}$ hypervalent iodine oxidation of 1 trimethylsilyloxy-2-oxa[n.1.0] cycloalkanes. Tetrahedron Letters 31, 197-200, doi:https://doi.org/10.1016/S0040-4039(00)94369-7 (1990).

2 Attaluri, S. et al. DNA adducts of aristolochic acid II: total synthesis and site-specific mutagenesis studies in mammalian cells. Nucleic Acids Research 38, 339-352, doi:10.1093/nar/gkp815 (2009).

3 Zheng, G. Q., Zhang, J., Kenney, P. M. \& Lam, L. K. T. in Food Phytochemicals for Cancer Prevention I Vol. 546 ACS Symposium Series Ch. 18, 230-238 (American Chemical Society, 1993).

4 Dubost, C. Preparation of 1-methyl-3-dihalomethyl-5-halopyrazole(thio)benzofuranyl carboxamide derivatives as fungicides useful in crop protection. WO2013167551A1 (2013).

5 Greul, J. N. et al. 5- HALOGENOPYRAZOLE BENZOFURANYL CARBOXAMIDES. US20150094350A1 (2015).

6 Hung, T. V., Mooney, B. A., Prager, R. H. \& Tippett, J. M. Central nervous system active compounds. VII. Phthalide synthesis by lithiation of alkoxyaromatics. Australian Journal of Chemistry 34, 383-395 (1981).

7 Menear, K. A. et al. Preparation of 4-[3-(4-cyclopropanecarbonyl-piperazine-1-carbonyl)-4fluoro-benzyl]-2H-phthalazin-1-one and its crystal forms as PARP-1 inhibitors. WO2008047082A2 (2008).

8 Denny, W. A., Rewcastle, G. W. \& Baguley, B. C. Potential antitumor agents. 59. Structureactivity relationships for 2-phenylbenzimidazole-4-carboxamides, a new class of minimal DNA-intercalating agents which may not act via topoisomerase II. Journal of Medicinal Chemistry 33, 814-819, doi:10.1021/jm00164a054 (1990).

9 Norman, M. H., Kelley, J. L. \& Hollingsworth, E. B. Conformationally restricted analogs of remoxipride as potential antipsychotic agents. Journal of Medicinal Chemistry 36, 3417-3423, doi:10.1021/jm00074a023 (1993).

10 Appari, R. D. et al. Preparation of aminopyrimidine derivatives for use as antitumor agents. WO2010141406A2 (2010).

11 Maechling, S. et al. Preparation of (difluoromethylnicotinic)indanyl carboxamides as fungicides. WO2014095675A1 (2014).

12 Vila, N. et al. Synthesis, biological evaluation and molecular modeling studies of phthalazin$1(2 \mathrm{H})$-one derivatives as novel cholinesterase inhibitors. RSC Adv. 6, 46170-46185, doi:10.1039/C6RA03841G (2016).

13 da Settimo, A. et al. Reinvestigation of reductive butylation of aminophthalimides: new compounds with local anesthetic activity. European Journal of Medicinal Chemistry 24, 263270, doi:https://doi.org/10.1016/0223-5234(89)90008-1 (1989).

14 Beck, D. E. et al. Synthesis and Biological Evaluation of New Carbohydrate-Substituted Indenoisoquinoline Topoisomerase I Inhibitors and Improved Syntheses of the Experimental Anticancer Agents Indotecan (LMP400) and Indimitecan (LMP776). J. Med. Chem. 57, 14951512, doi: $10.1021 / \mathrm{jm} 401814 \mathrm{y}$ (2014).

15 Sugiura, T. et al. Synthesis of a Novel Serotonin-3 (5-HT3) Receptor Antagonist. Synlett 1992, 531-533, doi:10.1055/s-1992-21405 (1992).

16 Pereira, L. W. et al. The Antileishmanial Potential of C-3 Functionalized Isobenzofuranones against Leishmania (Leishmania) Infantum Chagasi. Molecules 20, doi:10.3390/molecules201219857 (2015). 
17 Qiang, X. et al. DL-3-n-butylphthalide-Edaravone hybrids as novel dual inhibitors of amyloid$\beta$ aggregation and monoamine oxidases with high antioxidant potency for Alzheimer's therapy. Bioorganic \& Medicinal Chemistry Letters 27, 718-722, doi:https://doi.org/10.1016/j.bmcl.2017.01.050 (2017).

18 Cushman, M. S., Nguyen, T. X. \& Conda-Sheridan, M. M. Synthesis and use of N-substituted indenoisoquinoline compounds as dual tyrosyl-DNA phosphodiesterase I (Tdp1)topoisomerase I (Top1) inhibitors. US20130345252A1 (2013).

19 Cinelli, M. A. et al. Design, Synthesis, and Biological Evaluation of 14-Substituted Aromathecins as Topoisomerase I Inhibitors. Journal of Medicinal Chemistry 51, 4609-4619, doi:10.1021/jm800259e (2008).

20 Klein, M., Mederski, W., Tsaklakidis, C. \& Beier, N. Preparation of imidazo[1,2-a]pyrimidines as antidiabetic agents. WO2009049731A1 (2009).

21 Narahari Babu, A., Srinivas Goud, V., Gaonkar, S. L., Manjunatha, S. G. \& Kulkarni, A. K. One pot synthesis of citalopram from 5-cyanophthalide. WO2005077927A1 (2005).

22 Wiffen, J. \& Wilson, I. Preparation of leukotriene receptor agonist compounds and their intermediates. WO2008035086A2 (2008).

23 Teixeira, R. R. et al. Synthesis and Antiproliferative Activity of C-3 Functionalized Isobenzofuran-1(3H)-ones. Molecules 18, doi:10.3390/molecules18021881 (2013).

24 Beak, P. \& Snieckus, V. Directed lithiation of aromatic tertiary amides: an evolving synthetic methodology for polysubstituted aromatics. Accounts of Chemical Research 15, 306-312, doi:10.1021/ar00082a002 (1982).

25 Hayat, S., Atta ur, R., Choudhary, M. I., Khan, K. M. \& Bayer, E. An improved method for the synthesis of $\gamma$-lactones using sodium bromate and sodium hydrogen sulfite. Tetrahedron Letters 42, 1647-1649, doi:https://doi.org/10.1016/S0040-4039(00)02341-8 (2001).

26 Berti, G., Da Settimo, A. \& Livi, O. The nitration of some methyl substituted indole-3aldehydes. Tetrahedron 20, 1397-1405, doi:https://doi.org/10.1016/S0040-4020(01)99133-1 (1964).

27 Hromatka, O., Knollmüller, M. \& Foroutan-Rad, M. Über die Synthese des 2,3,4,8-Tetrahydro [1] benzoxepino [5,4,3-ef]-1,4-benzodiazepin-3-ons. Monatshefte für Chemie / Chemical Monthly 105, 1057-1066, doi:10.1007/BF00910273 (1974).

28 Isse, A. A., Lin, C. Y., Coote, M. L. \& Gennaro, A. Estimation of Standard Reduction Potentials of Halogen Atoms and Alkyl Halides. The Journal of Physical Chemistry B 115, 678-684, doi:10.1021/jp109613t (2011).

29 Saikia, I., Borah, A. J. \& Phukan, P. Correction to Use of Bromine and Bromo-Organic Compounds in Organic Synthesis. Chemical Reviews 116, 8312-8312, doi:10.1021/acs.chemrev.6b00410 (2016).

30 Ninkovic, S. et al. Preparation of heterocyclylaminopyrazine derivatives for use as CHK-1 inhibitors. WO2010016005A1 (2010).

31 Barnett, H. A. et al. Pyrazolecarboxamide compounds useful in the treatment of inflammatory, allergic and autoimmune diseases and their preparation. WO2007144327A2 (2007).

32 Reddy, G. S., Chen, H.-Y. \& Chang, I. J. Cysteine-Specific Blue Fluorescence Probe. Journal of the Chinese Chemical Society 53, 1303-1308, doi:10.1002/jccs.200600174 (2006). 